\title{
Proceeding
}

Supplementary Issue: Rio 2016 Olympic Games Second Anniversary Special Edition. Olympic Studies Forum, 2-3 October 2018.

Federal University of Espirito Santo, (Vitória - Espirito Santo), Brazil

\section{Meanings about soccer in the vision of athletes from youth teams}

\author{
DANIELE LINDERN , FERNANDA FAGGIANI, ARIELA MESTER, CAROLINA SARAIVA DE MACEDO \\ LISBOA
}

School of Health Sciences, Pontifical Catholic University of Rio Grande do Sul (PUCRS), Porto Alegre, Brazil

\begin{abstract}
This study aimed to understand the meaning of soccer in the life of young soccer athletes. The participants were four athletes of a soccer club in South Brazil. These athletes came from different States of the country. A semi-structured interview was conducted, and the data were analyzed through Content Analysis methodology. It was found that these athletes experience a series of changes - such as moving from their hometown, meeting different people, facing hard and demanding routines - pursuing the goal of becoming a professional soccer player. The results of this study point to the importance of a Psychology analysis and approach that aims to understand not only the risk factors to which these young soccer players are exposed, but also know the personal meanings they attribute to their practice and role as soccer players. Keywords: Sports health; Adolescent; Adjustment.
\end{abstract}

\section{Cite this article as:}

Lindern, D., Faggiani, F., Mester, A., \& de Macedo, C.S. (2019). Meanings about soccer in the vision of athletes from youth teams (in Portuguese). Journal of Human Sport and Exercise, 14(3proc), S348S357. doi:https://doi.org/10.14198/ihse.2019.14.Proc3.08

Corresponding author. Av. Protásio Alves, 8201/Torre 5 - apartamento 807 - Alto Petrópolis. CEP 91260-000 - Porto Alegre $-R S$, Brazil.

E-mail: daniele.lindern@gmail.com

Supplementary Issue: Rio 2016 Olympic Games Second Anniversary Special Edition. Olympic Studies Forum, 2-3 October 2018. Federal University of Espírito Santo, (Vitória - Espírito Santo), Brazil.

JOURNAL OF HUMAN SPORT \& EXERCISE ISSN 1988-5202

(c) Faculty of Education. University of Alicante

doi:10.14198/jhse.2019.14.Proc3.08

S348 | 2019 | Proc3 | VOLUME 14

(C) 2019 University of Alicante 


\section{INTRODUÇÃO}

A paixão pelo futebol é um valor cultural presente desde a infância e pode influenciar o convívio social e a formação da identidade dos indivíduos, especialmente daqueles que desde cedo vêem neste esporte uma expectativa de profissionalização. Esta influência exercida pelo futebol na vida das pessoas é reforçada pela mídia, que apresenta histórias de superação e sucesso de atletas e/ou equipes de futebol. Assim, a relação futebol/socialização/mídia resulta numa glamorização e fascínio pelo esporte, dando origem à ideia ou ilusão de certa garantia de sucesso profissional oriundo desta prática esportiva, o que leva jovens aspirantes ao futebol profissional a buscarem esse esporte como possibilidade de ascensão social e financeira, principalmente para as crianças mais pobres (Ciampa et al., 2010; Soares et al., 2011).

Para chegarem ao nível profissional, os atletas de futebol passam pelas categorias de base, que contemplam atletas de 12 a 20 anos de idade. As categorias de base recrutam atletas de diferentes Estados, que em busca do sonho de se tornarem jogadores de futebol profissional, ficam distantes geograficamente de sua familia dentre outras concessões/sacrifícios. Muitos destes atletas que se mudam de Estado ficam hospedados nas residências esportivas dos próprios clubes de futebol. Os jovens recrutados, geralmente, são oriundos de classes populares e médias, e despendem significativamente seu tempo nessa carreira em um mercado muito competitivo (Soares et al., 2011). A formação de um jogador de base pode levar, em média, de 5.000 a 6.000 horas de treinamento (Melo, 2010). Os atletas de categorias de base, portanto, buscam no futebol a esperança de uma vida melhor e recebem reforço/estímulo de amigos e familiares. Estes jovens atletas acreditam nas informações - distorcidas - passadas pela mídia, que mostram apenas a pequena parcela de jogadores que tiveram sucesso em sua trajetória (Ciampa et al., 2010).

Apesar de haver muitos clubes de futebol no Brasil, poucos deles oferecem salários compatíveis com os sonhos dos atletas aspirantes a profissionais. Em 2012, dos 30.784 jogadores registrados no país, 82\% jogavam sem remuneração ou recebiam, no máximo, até dois salários mínimos (Calil, 2012). Vinte clubes do Brasil reúnem $90 \%$ da preferência dos torcedores (Damo, 2007), indicando uma redução dos postos de trabalho bem remunerados - considerando que é a preferência dos torcedores que determina o potencial de venda de produtos dos clubes e possibilitando melhores ou piores condições aos jogadores destes clubes (Soares et al., 2011). Como já referido, o futebol profissional passa a ser, então, um sonho almejado por muitos atletas; no entanto, torna-se palpável para poucos (Ciampa et al., 2010).

A distância da família e amigos, cobrança elevada nos treinamentos e competições e dificuldade em conciliar os estudos e a vida esportiva podem ser obstáculos que permeiam o processo que estes atletas passam. A distância da família pode estar relacionada a um baixo desempenho e até mesmo à evasão escolar (Faggiani et al., 2016; Marques e Samulski, 2009). No entanto, mesmo distantes da família, os atletas podem receber apoio da mesma (Lee e Kartika, 2014; Marques e Samulski, 2009), podendo ser considerado um fator protetivo neste contexto.

Os fatores de risco vivenciados pelos atletas de categorias de base dizem respeito às pressões e ao estresse do cotidiano da prática esportiva e não são explicitados ou enfatizados pela cultura, mídia ou mesmo profissionais desta área. A expectativa em alcançar o profissionalismo influencia não somente a construção da identidade do atleta, mas também representa os sonhos de sua família. Estes jovens cobram um bom desempenho para si e são cobrados também pelos técnicos, família e torcedores (Ciampa et al., 2010). Estas pressões podem gerar estresse, dentre outros fatores de risco que afetam o desempenho e a saúde mental dos atletas de forma mais ampla (Faggiani e Lisboa, 2017; Brandão et al., 2012). 
A pressão decorrente da cobrança por resultados pode ser compreendida como um fator de risco aos atletas, uma vez que pode influenciar de maneira negativa em seu desempenho. A distância da família e dos amigos, assim como viver e se adaptar a ambientes culturalmente diferentes ao seu de origem, também podem ser compreendidos como fatores de risco, fato denotado pelo elevado índice de atletas de futebol profissional brasileiro que regressam ao país antes do término do contrato de trabalho por dificuldades de adaptação. No ano de 2010, por exemplo, 1029 jogadores profissionais foram expatriados, dos quais $683(66 \%)$ regressaram ao Brasil antes de finalizarem o primeiro ano de trabalho no exterior (Brandão et al., 2013).

Nesse contexto, torna-se também relevante conhecer os fatores potencialmente protetivos para estes jovens, como, por exemplo, a convivência em um ambiente pró-social, o planejamento de jogadas que realizará e rotina de treinos; bem como a aprendizagem de competências sociais, cognitivas e emocionais, como respeitar os outros atletas, não deixar-se abalar pela torcida adversária e lidar com regras. Ainda, podem também ser compreendidos como fatores de proteção para estes atletas: reconhecer-se em modelos positivos, como técnicos, professores e colegas; experimentar a esperança de um futuro melhor financeiramente; a busca de oportunidades junto às expectativas de sucesso para o futuro, que oportunizam uma chance para mostrar seu potencial e ascender socialmente; assim como vivenciar as responsabilidades que estes atletas têm de assumir, sejam o cumprimento de treinos e horários, lidar com patrocinadores, cuidado com sua forma física, dentre outros (Faggiani e Lisboa, 2017; Fontes e Brandão, 2013; Rutter, 1987; Sanches, 2007).

Torna-se fundamental, então, discutir o processo de resiliência para estes jovens. Considerando a presença dos fatores de risco e de proteção presentes no contexto do futebol de alto rendimento, é importante que haja uma reflexão a respeito das especificidades deste contexto e desta população para que sejam fomentadas estratégias de intervenção preventivas adequadas às demandas dos atletas. Desta forma, 0 objetivo deste trabalho foi compreender o significado do futebol na vida de atletas de categorias de base de um clube de futebol do Brasil, bem como conhecer suas expectativas em relação ao esporte e as principais dificuldades de adaptação e ganhos relacionados à mudança de seu Estado de origem.

\section{MATERIAL E MÉTODOS}

\section{Participantes}

Participaram deste estudo quatro atletas das categorias de base de um clube de futebol da Região Sul do Brasil, com idades entre 16 e 20 anos, moradores da residência esportiva do clube. A seleção dos participantes visou a contemplar atletas com características diversificadas, como idade (pressupôs-se que os participantes mais velhos teriam maior experiência prévia em outros clubes de futebol), tempo em que residiam na residência esportiva e Estado de origem. Todos os participantes são naturais de outros Estados do Brasil, sendo dois atletas da região Nordeste (Piauí e Sergipe) e dois atletas da região Sudeste (Espírito Santo e Rio de Janeiro). A tabela 1 apresenta a caracterização dos participantes do estudo.

Tabela 1. Caracterização dos participantes do estudo

\begin{tabular}{|c|c|c|c|c|}
\hline Identificação & Idade & $\begin{array}{l}\text { Estado de } \\
\text { origem }\end{array}$ & $\begin{array}{l}\text { Tempo de moradia na } \\
\text { residência esportiva }\end{array}$ & $\begin{array}{l}\text { Já jogou em categorias de base de } \\
\text { outros clubes }\end{array}$ \\
\hline Participante 1 (P1) & 20 & Espírito Santo & 1 ano e 3 meses & \multirow{4}{*}{ Sim } \\
\hline Participante 2 (P2) & 16 & Piauí & 2 anos e 3 meses & \\
\hline Participante 3 (P3) & 19 & Rio de Janeiro & 11 meses & \\
\hline Participante 4 (P4) & 16 & Sergipe & 1 mês e 3 semanas & \\
\hline
\end{tabular}




\section{Medidas}

Foi utilizada uma ficha de dados de identificação, na qual constavam informações como, por exemplo, nome, idade, naturalidade e escolaridade. Além disso, foi conduzida uma entrevista semiestruturada, composta pelas seguintes questões: (1) Significado do futebol para o atleta; (2) Expectativas com o futebol; (3) Percepção e adaptação da mudança de seu Estado original para o Rio Grande do Sul; (4) Dificuldades e facilidades acarretadas pela mudança para Porto Alegre; (5) Percepção sobre o quanto o atleta de futebol é preparado para o enfrentamento de uma cultura diferente da sua; (6) Exemplo de uma experiência que passou (positiva ou negativa) em relação à nova cultura em que se inseriu; (7) Pontos que considera importantes de serem passados para um atleta quando sai de sua cidade para ir morar e jogar em outra culturalmente diferente.

\section{Procedimentos éticos e de coleta de dados}

Após a aprovação do presente estudo em um Comitê de Ética em Pesquisa (Parecer n 1.021.701/2015) e os participantes selecionados consentirem em participar do estudo, estes foram informados sobre os objetivos do mesmo e então foi feita a marcação dos dias e horários para coleta de dados. Foi realizada uma entrevista semiestruturada com cada atleta por duas pesquisadoras deste estudo. Todas as entrevistas foram gravadas e posteriormente transcritas.

\section{Procedimentos para análise dos dados}

As entrevistas foram gravadas em áudio após a autorização do participante, e posteriormente, transcritas. A análise dos dados possibilitou a identificação de conteúdo que foram codificados através do método de Análise de Conteúdo (Bardin, 2011). Inicialmente, as entrevistas transcritas foram lidas e os pontos de destaque da leitura inicial - leitura flutuante (Bardin, 2011) - foram grifados. Os grifos foram passados para um arquivo adicional às entrevistas, caracterizando o processo de codificação, onde foram definidas as unidades de registro por meio da elucidação de temas (frases), considerando que o tema é a unidade de registro geralmente utilizada para respostas a questões abertas, entrevistas individuais, dentre outros tipos de documento (Bardin, 2011), sendo adequada para análise das entrevistas deste estudo. As frases grifadas das entrevistas receberam quatro cores - uma para cada participante - para distinguir as falas dos diferentes atletas, e foram alocadas em unidades de contexto, que servem como compreensão para codificar a unidade de registro, sendo uma dimensão superior às unidades de registro, visando ao entendimento exato destas unidades (Bardin, 2011). Desta forma, foram definidas oito unidades de contexto: (A) Significado do futebol na vida do atleta; (B) Expectativas com o futebol; (C) Como encarou mudança de Estado; (D) Como foi adaptação e o que acha importante para se adaptar a uma nova cultura; (E) Aspectos positivos da mudança; (F) Preparação do atleta para enfrentar uma cultura diferente da sua; $(G)$ Exemplo de situação que passou na nova cultura e $(\mathrm{H}) \mathrm{O}$ que é importante que um atleta saiba ao se mudar.

Após a definição das unidades de contexto foi escolhida a regra de enumeração por frequência, por considerar-se, para este estudo, que a importância da unidade de registro aumenta de acordo com a frequência de sua aparição (Bardin, 2011). Esta etapa foi realizada utilizando-se como código uma letra seguida de um número, em que a letra foi definida de acordo com o tema a que a frase pertencia (por exemplo, as frases pertencentes ao tema "Significado do futebol na vida do atleta" foram codificadas com a letra "A"), e o número indica que a frase pertence a um determinado eixo dentro de um determinado tema (por exemplo, o código "A1" indica que a frase foi codificada pelo tema "A" e o número "1" demarca a ocorrência de expressões que abarquem o significado de que o futebol "é mais que uma profissão", então todas as ocorrências de frases que compreendam esse significado receberam o código "A1"). Após a codificação com letras e números, foram calculadas as frequências de cada código. As unidades de contexto 
serviram como base para os códigos iniciais, que foram condensados por similaridade e deram origem aos eixos.

\section{RESULTADOS E DISCUSSÃO}

A Tabela 2 apresenta os principais resultados da etapa de codificação, contendo os temas e as frequências das unidades de registro, bem como os eixos elaborados a partir das unidades de contexto.

Tabela 2. Frequência das unidades de registro por temas e eixos

\begin{tabular}{|c|c|c|c|c|}
\hline Eixos & $\begin{array}{l}\text { Códigos } \\
\text { das UR }\end{array}$ & $\begin{array}{l}\text { F das } \\
\text { UR }\end{array}$ & Temas das UR & Unidades de contexto \\
\hline \multirow{6}{*}{$\begin{array}{l}\text { Perspectivas } \\
\text { identitárias } \\
\text { futebol na vida } \\
\text { atleta }\end{array}$} & A3 & 8 & $\begin{array}{l}\text { Tudo o que faz é pelo futebol; vive para o futebol; é a vida } \\
\text { que quer }\end{array}$ & \multirow{2}{*}{$\begin{array}{l}\text { (A) Significado do futebol } \\
\text { na vida do atleta }\end{array}$} \\
\hline & A4 & 4 & O futebol é seu sonho & \\
\hline & $\mathrm{B} 1$ & 4 & Ajudar sua família & \multirow{4}{*}{$\begin{array}{l}\text { (B) Expectativas com } 0 \\
\text { futebol }\end{array}$} \\
\hline & B2 & 3 & $\begin{array}{l}\text { Ser um grande jogador de futebol; jogar na seleção } \\
\text { brasileira }\end{array}$ & \\
\hline & B3 & 2 & Criar uma família através do futebol & \\
\hline & B9 & 2 & Querer uma vida e moradia melhores & \\
\hline \multirow{13}{*}{$\begin{array}{l}\text { Dificuldades } \\
\text { facilidades } \\
\text { decorrentes } \\
\text { mudança } \\
\text { Estado }\end{array}$} & $\mathrm{C} 1$ & 5 & Maior dificuldade foi o clima frio & \multirow{3}{*}{$\begin{array}{l}\text { (C) Como encarou } \\
\text { mudança de Estado }\end{array}$} \\
\hline & $\mathrm{C} 2$ & 2 & Tinha uma expectativa boa antes de chegar & \\
\hline & C5 & 3 & $\begin{array}{l}\text { Encarou a mudança de forma normal/ não sentiu } \\
\text { dificuldade }\end{array}$ & \\
\hline & $\mathrm{D} 1$ & 3 & $\begin{array}{l}\text { Dificuldade de adaptação inicial com o clima frio, mas é } \\
\text { preciso superar/ Se adapta rápido ao clima }\end{array}$ & \multirow{4}{*}{$\begin{array}{l}\text { (D) Como } \\
\text { adaptação }\end{array}$} \\
\hline & $\mathrm{D} 2$ & 3 & $\begin{array}{l}\text { Adaptou-se bem às pessoas, principalmente colegas da } \\
\text { residência esportiva }\end{array}$ & \\
\hline & D3 & 3 & $\begin{array}{l}\text { Não apresentou dificuldade de adaptação ou pouca } \\
\text { dificuldade de adaptação }\end{array}$ & \\
\hline & D4 & 4 & Dificuldade em deixar a família, mas se adaptou bem & \\
\hline & E1 & 2 & $\begin{array}{l}\text { Facilidade em fazer amizades; amizade com pessoas de } \\
\text { culturas diferentes }\end{array}$ & \multirow{3}{*}{$\begin{array}{l}\text { (E) Aspectos positivos da } \\
\text { mudança }\end{array}$} \\
\hline & E3 & 2 & $\begin{array}{l}\text { Cidade bonita/ legal; dá pra fazer coisas interessantes } \\
\text { sem gastar ou gastando pouco }\end{array}$ & \\
\hline & E4 & 3 & $\begin{array}{l}\text { Estar aqui já é um sonho, vários meninos gostariam de } \\
\text { ter essa oportunidade/lsso representa a chance de um } \\
\text { bom futuro }\end{array}$ & \\
\hline & $\mathrm{F} 1$ & 4 & $\begin{array}{l}\text { O atleta tem que estar preparado para mudanças de local } \\
\text { e clube; o atleta tem que ser como um "camaleão" }\end{array}$ & \multirow{3}{*}{$\begin{array}{l}\text { (F) Preparação do atleta } \\
\text { para enfrentar cultura } \\
\text { diferente da sua }\end{array}$} \\
\hline & $\mathrm{F} 2$ & 2 & Foi preparado pela família que o apoiou & \\
\hline & $\mathrm{F} 4$ & 4 & $\begin{array}{l}\text { Não houve uma preparação formal quando chegou, mas } \\
\text { a convivência com os colegas da residência esportiva foi } \\
\text { uma experiência positiva para adaptação à cultura }\end{array}$ & \\
\hline \multirow{2}{*}{$\begin{array}{ll}\text { Compreensão do } \\
\text { processo de } \\
\text { adaptação em uma }\end{array}$} & $\mathrm{G} 2$ & 2 & $\begin{array}{l}\text { Oportunidade de estar em um clube onde é visado, } \\
\text { sendo este o sonho de alguns meninos }\end{array}$ & $\begin{array}{l}\text { (G) Exemplo de situação } \\
\text { que passou na nova } \\
\text { cultura }\end{array}$ \\
\hline & $\mathrm{H} 2$ & 2 & Falar como é o grupo & \\
\hline
\end{tabular}




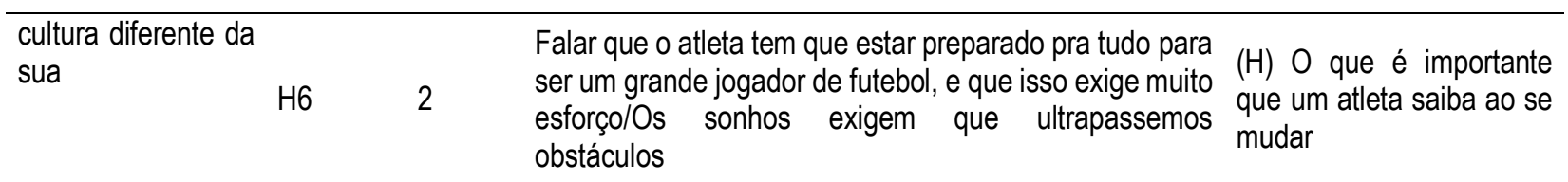

Note: UR: Unidade de Registro. F: Frequência.

O primeiro eixo emergente das unidades de contexto foi "Perspectivas identitárias do futebol na vida do atleta". Conforme explanado na seção de introdução, o futebol está fortemente ligado aos valores culturais no Brasil, influenciando a formação da identidade, seja daqueles que buscam o futebol como profissão, hobby ou simplesmente como torcedores. Além disso, é fonte de elevadas expectativas de mudança de vida, sendo, para alguns, a única esperança de uma vida socioeconômica e culturalmente melhor (Ciampa et al., 2010). Nesta perspectiva, os participantes 1 e 4 relataram: "Eu acho que [o futebol] é mais que uma profissão né, é como se fosse uma paixão, uma vida, porque tudo o que eu faço é pelo futebol, então basicamente a minha vida é o futebol [...] [espero poder] ajudar a minha família, poder jogar na seleção brasileira, jogar... Criar uma familia através do futebol, sabe? Construir uma família através dos grandes do futebol. É meu sonho, então... acho que é isso. Mas é viver do futebol" (P1). "O futebol é meu sonho. É um modo que eu tenho de tirar a minha família do jeito que ela é agora. É, deixa eu ver... Futebol é um modo que eu possa dar uma vida melhor pra minha família. É o único modo que eu posso fazer" (P4 - Grifo da autora).

O participante 4 enfatiza que a carreira do futebol é a única maneira de proporcionar mais qualidade de vida para sua família, transparecendo o dilema ainda presente no Brasil de que o futebol deve ser a única prioridade na vida daqueles que estão em busca deste sonho, deixando para trás, por vezes, os estudos ainda que este não seja o caso deste atleta. Este dado pode denotar um fator de risco para o abandono escolar, já que os atletas priorizam o esporte não somente por caracterizar-se como a potencial concretização de um sonho, mas também por ser uma responsabilidade de trabalho onde são cobrados por alto desempenho. Neste sentido, os resultados do estudo de Marques e Samulski (2009), realizado com 186 atletas de categorias de base no Brasil, apontaram que a maior parte dos atletas estava atrasada no que se refere ao ano escolar correspondente à idade, e mais da metade destes pararam de estudar em algum momento para que pudessem se dedicar ao futebol (Marques e Samulski, 2009). A elevada carga horária de treinamentos se equipara com a carga horária escolar, tornando suas rotinas cansativas, e podendo, assim, ser um obstáculo no processo de escolarização (Soares et al., 2011). Reconhecendo que a rotina de treinos pode prejudicar a assiduidade e desempenho escolar de jogadores menores de 18 anos, em 2011 foi sancionada uma lei estadual que obriga os clubes de futebol registrados na Federação Gaúcha de Futebol a acompanhar a matrícula e frequência destes atletas, havendo penalidade para aqueles clubes que não cumprirem a lei (Projeto de Lei $n^{0} 73 / 2011$ de 28 de abril da Assembleia Legislativa do Estado do Rio Grande do Sul, 2011).

Em contraponto, o participante 3 demonstra uma visão mais ponderada e realista, compreendendo o futebol como uma possibilidade de crescimento, mas ao mesmo tempo como uma profissão instável: "Quando eu era menorzinho eu tinha o sonho de vestir a camisa da seleção brasileira, querendo ou não fazer um nome, ser famoso. Mas hoje eu já penso totalmente diferente, apesar do que aconteceu com a minha lesão, fez com que eu mudasse bastante o meu pensamento. Eu vi que carreira de jogador é uma coisa muito rápida, que de dia pro outro, eu posso ir ali treinar agora e acabar minha carreira. Então eu penso mais em fazer uma estabilidade financeira pra poder ajudar meus pais e, querendo ou não, depois que terminar a carreira, continuar, prosseguir com os recursos que eu consegui durante a carreira, entendeu?" (P3). Deve-se levar em consideração, no entanto, que o participante 3 é um dos mais velhos dos atletas entrevistados (19 anos 
de idade na ocasião da entrevista), tendo passado por diversos clubes de futebol e por vivências que 0 fizeram ressignificar o esporte na sua vida. Seu relato mostra a passagem de uma visão mais idealizada do mundo futebolístico para uma visão mais realista do futebol enquanto profissão, levando em consideração a irrisória oferta de postos de trabalho bem remunerados deste mercado em contraste com a alta procura de jovens que sonham com uma vida financeiramente melhor (Soares et al., 2011).

O sonho de jogar na seleção brasileira, que aparece também na fala do participante 3 , foi relatado por outros dois participantes (Tabela 2, código B2), assim como a expectativa de ajudar financeiramente a família, que foi relatada por todos os participantes (Tabela 2, código B1). Muitos meninos que moram na residência esportiva do clube onde foram realizadas as entrevistas ajudam financeiramente suas famílias, sendo que alguns deles, de acordo com a equipe multidisciplinar das categorias de base, mandam todo o dinheiro que recebem para seus familiares. Assim, para muitos, o futebol é a única maneira de proporcionar uma vida melhor para si e para sua família, no entanto, nem todos os atletas conseguirão seguir nesta carreira. De acordo com o estudo de Marques e Samulski (2009), 79,6\% dos 186 atletas participantes da pesquisa fazem parte da classe média baixa (renda de cinco a dez salários mínimos) ou classe baixa (renda de meio a dois salários mínimos), de acordo com os critérios do IBGE. Estes achados vão ao encontro das expectativas relatadas pelos atletas participantes do presente estudo acerca da busca de recursos financeiros que supram as necessidades de suas famílias.

O segundo eixo, denominada "Dificuldades e facilidades decorrentes da mudança de Estado" visou a compreender as particularidades relacionadas à mudança cultural pela qual os participantes do estudo passaram quando saíram de seu Estado de origem para a Região Sul. Uma das maiores dificuldades relatadas por todos os participantes deste estudo foi a adaptação ao clima frio, já que nas suas cidades de origem o calor é predominante: "Ah, principalmente em relação ao frio, minha cidade lá é muito quente, ai quando eu vim pra cá já sabia que ia fazer muito frio, pra me adaptar levou muito tempo, mas agora já ta melhor, né?" (P2). No entanto, apesar de ser a principal dificuldade de adaptação citada pelos participantes do estudo, o clima não se impõe a eles como uma barreira, aparentemente não representando um fator de risco para desadaptação.

O choque cultural da mudança da região Nordeste para a Região Sul fica evidente no relato do participante 4: "o povo aqui é meio estranho. Não é a alegria que tem lá no Nordeste não. Lá, 24h, todo mundo rindo, brincando. Aqui qualquer brincadeira os caras já incham a cara. Lá é todo mundo alegre. Pior eu que todo domingo lá na minha casa tem festa. A família feliz. Estranhei isso aqui também. Gaúcho não gosta muito de brincadeira não. Por isso que eu falo que meu mal é ser alegre demais." (P4). Entretanto, cabe ressaltar que este participante, na ocasião da entrevista, estava há apenas um mês e três semanas no clube, o que pode influenciar no mal-estar frente a uma cultura diferente, estando ainda em fase de adaptação. Ao mesmo tempo em que os participantes relataram estas dificuldades, compartilharam percepções de que o atleta deve estar preparado para estas e outras mudanças, e que o convívio com colegas da residência esportiva torna-se um potencial fator de proteção para adaptação e trocas culturais: "Com certeza, [o jogador de futebol] tem que ser [preparado], né. Porque o jogador de futebol não dura muito tempo em um lugar só, nunca sabe pra onde vai" (P1). "eu acho que eu me preparei mais foi dentro do alojamento, que eles falavam lá. Conhecer outras pessoas, acaba conhecendo outras culturas também, por outras pessoas. Igual eu, no meu quarto tem eu e o [colega de quarto] carioca, aí vem o [colega da residência] capixaba, o outro baiano, um gaúcho, o outro do Mato Grosso, então a gente vai se conhecendo, entendeu?" (P3). O apoio pode vir desde os colegas da residência esportiva, conforme relato do participante 3 , até a família, mesmo com a distância: "[...] acho que eu tava precisando da minha mãe e do meu pai mesmo, ver eles [para se sentir melhor quando chegou] [...]daí minha mãe falou 'então eu vou, vou te acalmar', ai depois meu pai veio e foi 
tranquilo [...] eu tenho uma família que sempre fala comigo, que me preparou pra essa mudança de tudo" (P1). "Só a dificuldade que eu tenho foi de deixar meus pais lá. [...] a saudade. [...] mas eu to me adaptando aos poucos" (P4).

Estes dados vão ao encontro dos estudos de Marques e Samulski (2009) e Lee e Kartika (2014), os quais constataram que mesmo à distância, os atletas sentem-se apoiados pelos pais, principalmente no que se refere aos aspectos emocionais e motivacionais. Além disso, o estabelecimento de vínculos reais, ou seja, com pessoas próximas como os demais atletas do alojamento, deve ser estimulado. Tal aproximação minimiza sentimentos de isolamento e auxilia no desenvolvimento de relações sociais, importantes para 0 processo de adaptação ao novo ambiente (Evans e Stead, 2014).

Ainda que os atletas acreditem que devam estar sempre prontos para possíveis mudanças, demonstraram que não recebem uma preparação formal para tal. No entanto, se quiserem progredir na carreira do futebol, a única escolha é se adaptar: "[o atleta não está preparado], mas tem que se preparar pra ser, se quer ser um jogador de futebol tem que ser um monte de coisa, se preparar pra tudo" (P2). "Preparado? Ah, não sei. O cara tem que ser meio... Como é aquele animal que... Camaleão. [...] Porque um dia tu pode tá lá na Bahia num calor, e outro dia tu vai ter que tá aqui. Lá na Bahia é um povo que xinga, grita, que são desorganizados, que deixam lixo em tudo que é lugar [...]. Ai tu vem pra cá, uma cultura totalmente diferente, o trânsito, tudo" (P3). Estes relatos denotam que, para adaptarem-se ao contexto futebolístico, é necessário que os atletas apresentem capacidade de resiliência frente aos fatores de risco da profissão e seu contexto, a qual terá maior probabilidade de se fazer presente naqueles que conseguirem enfrentar as angústias e incertezas ligadas a este tipo de prática esportiva (Brandão, 2000). Dessa forma, a capacidade de adaptação frente à nova cultura é uma das características mais importantes para um jogador de futebol expatriado (Brandão et al., 2013).

O terceiro eixo, "Compreensão do processo de adaptação em uma cultura diferente da sua", é caracterizada pelas perspectivas dos atletas entrevistados sobre o que gostariam de saber antes de terem se mudado, bem como por exemplos de situações que passaram na adaptação à nova cultura. Os participantes 2 e 4 salientaram como aspectos positivos a visibilidade que têm no clube atual, sendo uma possível oportunidade de crescimento: "coisa positiva é quando eu tava no Ceará assim, não tinha ninguém olhando a gente jogando, aí quando eu cheguei aqui que a gente foi ter um jogo, aí o cara da seleção brasileira tava aí, eu joguei eu fui colocado na seleção brasileira" (P2). "só de tá aqui já é positivo já. Porque é meu futuro, lá um monte de moleque tem o sonho de tá aqui e não tem, e eu to tendo" (P4).

Como sugestões a respeito das informações que seriam interessantes de serem passadas aos atletas em fase de mudança de clube para um local culturalmente diferente, os participantes relataram como relevantes o conhecimento do grupo que irão conviver: "Saber como o grupo é" (P1). "As características dos jogadores daqui é muito integrada é muito diferente de lá da onde eu tava, aqui é mais regrado assim mais corpo a corpo essas coisas" (P2). A abordagem motivacional também se destacou, aparecendo nas falas dos participantes 2 e 3: "[...] tem que se preparar pra tudo se quer ser um homem na vida, um grande jogador de futebol" (P2). "[É importante falar para os atletas] Que não é fácil. Não é fácil, mas a força de vontade né, foi o que eu falei, sai de lá com os sonhos tão grandes que isso, viraram obstáculos assim, mas que eu consegui ultrapassar tranquilo" (P3). Não somente estes relatos dos participantes 2 e 3, como também outros apresentados, demonstram que para seguir seus sonhos, estes atletas saem de seu lar muito cedo e compartilham quartos e vidas com outros atletas em busca de sonhos semelhantes, tendo de abrir mão do contato pessoal com a família, amigos e por vezes de sua privacidade. Tais aspectos caracterizam responsabilidades de um adulto, no entanto são a realidade de muitos adolescentes no contexto futebolístico 
brasileiro. Em concordância com um estudo brasileiro realizado com 56 atletas das categorias de base do Sport Club Internacional de Porto Alegre, em que seis atletas foram entrevistados, os jogadores afirmaram que seus principais sacrificios foram renunciar à vida pessoal, bem como aderir às concentrações e treinos excessivos (Freire Rodriges, 2004). Assim, os autores deste estudo compreendem a escolha pela carreira profissional do futebol como uma crença de que a profissão vai muito além da remuneração por ter um valor em si, sendo fonte de sentido e autorrealização (Freire Rodriges, 2004). Estas percepções também estiveram presentes nos relatos dos atletas entrevistados neste estudo, que veem no futebol não somente uma perspectiva de melhora financeira de vida, mas também uma prática repleta de significado e sentido.

\section{CONCLUSÕES}

Este estudo visou a compreender, pela perspectiva de atletas de categorias de base, os significados, percepções e expectativas acerca do futebol. Constatou-se que estes atletas vivenciam uma série de mudanças e deixam para trás afetos, cultura e outros valores em busca do objetivo de se tornarem um jogador de futebol profissional, na batalha por um sonho que envolve status e boa remuneração. Esta busca caracteriza-se, ao mesmo tempo, por frustrações, dificuldades e satisfação, na medida em que abrem mão do conforto e segurança de seu lar - independentemente de sua classe social - para morar junto a vários meninos que compartilham experiências e ao mesmo tempo vêm de culturas tão diversas.

A convivência com outros atletas possibilita uma rica troca de experiências, que serve como motivação e aprendizado, passando por adversidades distantes de sua família e junto a pessoas que desconhecem; no entanto, a esperança de uma vida melhor os motiva a seguir em frente. Os atletas de alto rendimento, especialmente no futebol, passam grande parte de seu desenvolvimento convivendo em um contexto onde o principal valor é o desempenho no esporte, sendo muitas vezes ignorados em sua subjetividade e reconhecidos somente por seus êxitos no esporte. Assim, os resultados deste estudo - apesar de apresentarem limitação pelo número de participantes entrevistados - apontam para a necessidade de um olhar que represente um diálogo da Psicologia Clínica e do Esporte acerca dos fenômenos que ocorrem na vida destes atletas, que vise a compreender não somente os fatores de risco a que estes jovens estão expostos, mas os significados que os mesmos atribuem a sua prática.

\section{REFERÊNCIAS}

Bardin, L. (2011). Análise de conteúdo. São Paulo: Edições 70.

Brandão, M. R. F. Fatores de stress em jogadores de futebol profissional. Tese de doutorado, Universidade Estadual de Campinas, Campinas, 2000. https://doi.org/10.17143/ciaed/xxillciaed.2017.00435

Brandão, M. R. F., Leite, G., Ferreira, R. A., Gomes, S. S., Pedrinelli, V. J., Oliveira, R. S. (2012). Percepção do estresse competitivo e cultura em futebolistas de três países participantes do Mundial de 2006: Brasil, Portugal e Arábia Saudita. Motricidade, 8, 925-936.

Brandão, M. R. F., Magnani, A., Medina, J. P., Tega, E. C. (2013). Além da cultura nacional: o expatriado no futebol. Revista Brasileira de Ciência e Movimento, 21, 177-182. https://doi.org/10.18511/01031716/rbcm.v21n2p177-182

Calil, L. (2012, 23 de set.). Triste realidade: no Brasil, $82 \%$ dos jogadores de futebol recebem até dois salários mínimos. Extra. https://doi.org/10.11606/t.5.2009.tde-08122009-175424

Ciampa, A. C., Leme, C. G., Souza, R. F. (2010). Considerações sobre a formação e transformação da identidade profissional do atleta de futebol no Brasil. Revista Diversitas - Perspectivas en Psicología, $6,27-36$. 
Damo, A. (2007). Do dom à profissão: a formação de futebolistas no Brasil e na França. São Paulo, Hucitec. https://doi.org/10.11606/issn.2316-9141.v0i163p393-402

Evans, A. B., Stead, D. E. (2012). 'It's long way to the super leaguw': The experiences of Australisian professional rugby league migrants in the United Kingdon. Int Rev Sociol Sport, 49, 707-727. https://doi.org/10.1177/1012690212464700

Faggiani, F., \& Lisboa, C. S. M. (2017). O processo de aculturação e a adultez emergente em atletas de futebol. Tese de Doutorado, Pontifícia Universidade Católica do Rio Grande do Sul, Porto Alegre, RS, Brasil. https://doi.org/10.24873/j.rpemd.2018.06.219

Faggiani, F., Lindern, D., Strey, A., Aiquel, P., F., Fulginiti, D. \& Lisboa, C., S., M. (2016). O Fenômeno do Expatriado no Contexto Esportivo. Psicologia: Ciência e Profissão, 36(3), pp. 738-747. https://doi.org/10.1590/1982-3703001832016

Freire Rodrigues, F. X. (2004). Modernidade, disciplina e futebol: uma análise sociológica da produção social do jogador de futebol no Brasil. Sociologias, 11, 260-299. https://doi.org/10.1590/s151745222004000100012

Fontes, R. D. C., Brandão, M. R. F. (2013). Resilience in sport: an ecological perspective on human development. Motriz, 19, 151-159. https://doi.org/10.1590/S1980-65742013000100015

Lee, L., Kartika, N. (2014). The influence of individual, family, and social capital factors on expatriate adjustment and performance: The moderating effect of psychology contract and organizational support. Expert Syst Appl, 41, 5483-5494. https://doi.org/10.1016/j.eswa.2014.02.030

Marques, M. P., Samulski, D. M. (2009). Análise da carreira esportiva de jovens atletas de futebol na transição da fase amadora para a fase profissional: escolaridade, iniciação, contexto sócio-familiar e planejamento da carreira. Revista Brasileira de Educação Física e Esporte, 23, 103-119. https://doi.org/10.31501/rbpe.v2i1.9275

Melo, L. (2010). Formação e escolarização de jogadores de futebol no Estado do Rio de Janeiro. 2010. Dissertação de mestrado, Universidade Gama Filho, Rio de Janeiro. https://doi.org/10.5327/z18063144201600040005

Coimbra, D.R. (2011). Validação do Questionário "Athletic Coping Skills Inventory-28 (ACSI-28)" para a Língua Portuguesa do Brasil. Dissertação de mestrado, Universidade Federal de Juiz de Fora, Juiz de Fora. https://doi.org/10.24873/j.rpemd.2019.05.445

Projeto de Lei $n^{0} 73$ /2011 de 28 de abril da Assembléia Legislativa do Estado do Rio Grande do Sul (2011). https://doi.org/10.17533/udea.iee.v33n1a18

Rutter, M. (1987). Psychosocial resilience and protective mechanisms. Am J Orthopsychiat, 37, 317-331. https://doi.org/10.1017/CB09780511752872.013

Sanches, S. M. (2007). A prática esportiva como uma atividade potencialmente promotora de resiliência. Revista Brasileira de Psicologia do Esporte, 1, 01-15. https://doi.org/10.31501/rbpe.v1i1.9256

Soares, A.J.G., Melo, L.B.S., Costa, F.R., Bartholo, T.L., \& Bento, J.O. (2011). Jogadores de Futebol no Brasil: Mercado, formação de atletas e escola. Revista Brasileira de Ciências do Esporte, 33, 905 921. https://doi.org/10.1016/i.rbce.2015.11.003

\section{(9) $\odot \Theta \Theta$}

This work is licensed under a Attribution-NonCommercial-NoDerivatives 4.0 International (CC BY-NC-ND 4.0). 